\title{
Hubungan Pengetahuan Lingkungan Hidup Terhadap Sikap Peduli Lingkungan Siswa SMPN 20 Depok
}

\author{
Annisa Handayani', Sri Murni Soenarno ${ }^{2 *}$, Zakiah Fithah A'ini ${ }^{1}$ \\ ${ }^{1}$ Fakultas MIPA, Pendidikan Biologi, Universitas Indraprasta PGRI \\ $2^{2 *}$ Fakultas Pascasarjana, Pendidikan MIPA, Universitas Indraprasta PGRI \\ *email:asmurnis@gmail.com
}

\begin{tabular}{l} 
Article History \\
\hline Received: \\
O1/01/2022 \\
Revised: \\
12/01/2022 \\
Accepted: \\
28/01/2022
\end{tabular}

Kata kunci:

Implementasi

materi

Kepedulian

lingkungan

Korelasi

Depok Jawa Barat

SMP Negeri

Key words:

Correlation

Depok West Java

Environmental care

Material

implementation

Public middle

school

\begin{abstract}
ABSTRAK
Siswa merupakan bagian dari masyarakat juga diharapkan memiliki kesadaran untuk melindungi lingkungan hidupnya. Kesadaran dan kepedulian siswa terhadap lingkungannya merupakan pengimplementasian materi yang telah disampaikan oleh gurunya. Penelitian ini bertujuan untuk mengetahui hubungan pengetahuan lingkungan hidup terhadap sikap peduli lingkungan hidup di SMPN 20 Depok, Jawa Barat. Penelitian ini dilakukan pada siswa kelas VII, VIII, dan IX yang berjumlah 275 siswa, dari total populasi 879 siswa. Penelitian dilaksanakan pada Maret hingga Juli 2021. Metode penelitian yang digunakan adalah pendekatan kuantitatif dengan metode survei korelasional. Uji normalitas pada penelitian ini menggunakan metode Kolmogorov Smirnov dengan hasil $a_{\max } \leq \mathrm{D}_{\text {tabel }}$ sehingga dapat dikatakan bahwa variabel pengetahuan lingkungan hidup dan sikap peduli lingkungan hidup berdistribusi normal. Dalam uji linearitas didapatkan hasil bahwa nilai $F_{\text {hitung }}<\mathrm{F}_{\text {tabel }}$ maka dapat diketahui bahwa model regresi berpola linear. Adapun persamaan korelasi yang diperoleh yaitu $\widehat{Y}=75.07+0.07 \hat{X}$. Hasil penelitian menunjukan bahwa pengetahuan lingkungan hidup dan sikap peduli lingkungan hidup yang dimiliki siswa di SMPN 20 Depok termasuk dalam kategori tinggi. Selain itu, terdapat korelasi dan adanya signifikan antara pengetahuan dengan sikap peduli terhadap lingkungan hidup dari siswa di SMPN 20 Depok dengan tingkat keeratan hubungan yang termasuk kategori sangat rendah dengan arah hubungan positif. Pihak sekolah dan guru perlu mengadakan kegiatan rutin terkait menjaga kelestarian di lingkungan sekolah agar siswa dapat lebih mengembangkan pengetahuan yang telah dimilikinya.
\end{abstract}

Copyright (C) 2022 LPPM Universitas Indraprasta PGRI. All Right Reserved 


\section{PENDAHULUAN}

Lingkungan adalah kesatuan tidak terpisah dari makhluk hidup yang terdiri dari manusia, hewan, dan tumbuhan. Kehidupan manusia sangat tergantung pada lingkungan hidup di mana mereka tinggal. Tingkat kesadaran masyarakat terhadap lingkungan termasuk upaya melindungi alam ternyata belum sepenuhnya menjadi kesadaran yang tertanam pada diri manusia (Hardiningtyas, 2016)

Siswa merupakan bagian dari masyarakat juga diharapkan memiliki kesadaran untuk melindungi lingkungan hidupnya. Ahmadi (2018) menyatakan bahwa siswa memiliki sikap peduli lingkungan sangat baik disebabkan oleh kegiatan yang rutin dilakukan oleh siswa, seperti membersihkan kelas dan mengelola serta menjaga lingkungan sekolah diatur dengan jelas dalam peraturan sekolah. Aminrad et al. (2013) menyatakan bahwa bila setiap pribadi memiliki pengetahuan yang mendalam mengenai lingkungan dan isu-isu yang terkait dengan lingkungan, maka akan muncul rasa kesadaran yang lebih terhadap lingkungan dan permasalahn di seputar lingkungan. Sirait (2012) dalam kesimpulan penelitiannya menyatakan bahwa terdapat kaitan antara pengetahuan dengan sikap peduli terhadap lingkungan yang signifikan. Hal ini bermakna, tingginya nilai pengetahuan lingkungan hidup maka akan berdampak terhadap nilai perilaku mencintai atau peduli lingkungan pada siswa, demikian juga sebaliknya. Azhar et al. (2015) telah meneliti adanya kaitan antara pengetahuan dan etika lingkungan dengan sikap dan perilaku menjaga kelestarian lingkungan. Martini (2019) juga melakukan penelitian yang senada dengan Munawar et al. (2019) yaitu mengkaji hubungan pengetahuan lingkungan dengan perilaku peduli atau prolingkungan peserta didik di sekolah Adiwiyata, yang ternyata program yang diterapkan di sekolah Adiwiyata berpengaruh positif mengubah perilaku prolingkungan. Muliana et al. (2018) meneliti mengenai hubungan pengetahuan lingkungan sikap siswa terhadap pengelolaan kebersihan di sekolah. Hasil penelitian menunjukkan tidak terdapat hubungan antara pengetahuan terhadap pengelolaan kebersihan para siswa di lingkungan sekolah.

Berdasarkan beberapa penelitian yang telah dilakukan oleh para peneliti sebelumnya, maka dipandang perlu dilakukan penelitian pendahuluan ini. Pada saat observasi awal sebelum penelitian ke SMPN 20 Depok, telah ditemukan sampah yang berserakan, baik di ruang kelas atau di lingkungan sekolah. Kurangnya keberadaan tanaman atau pepohonan di lingkungan sekolah sehingga kondisi sekolah terlihat gersang. Selain itu, masih ditemukannya siswa yang masih suka mencoretcoret di meja dan kursi menggunakan pulpen dan membawa makanan dari luar sekolah atau dari kantin ke dalam kelas yang kemudian sampah sisa makanan tersebut disimpan di dalam laci meja sebagai tempat pembuangan.

Penelitian yang telah dilakukan sebelumnya belum pernah meneliti tentang keterkaitan pengetahuan lingkungan dan kepedulian siswa terhadap lingkungan hidup di SMPN 20 Depok. Berdasarkan hasil observasi lapangan dilakukan penelitian yang bertujuan untuk mengkaji kaitan antara pengetahuan lingkungan hidup terhadap sikap peduli lingkungan hidup pada siswa di SMPN 20 Depok. Penelitian semacam ini perlu dilakukan guna meningkatkan kesadaran dan kepedulian siswa terhadap lingkungannya dimulai dari sekolahnya, karena hal itu merupakan bagian dari proses pendidikan dan pengimplementasian materi yang telah disampaikan oleh guru.

\section{METODE PENELITIAN}

Metode yang diterapkan dalam penelitian ini adalah metode pendekatan kuantitatif dan metode penelitian survei korelasional. Penelitian dilaksanakan pada bulan Maret hingga Juli 2021. Variabel independen $(\mathrm{X})$ penelitian ini adalah pengetahuan tentang lingkungan hidup, sedangkan variabel dependennya (Y) adalah sikap siswa terhadap lingkungan hidup. Penelitian ini melibatkan siswa kelas VII, VIII, dan IX SMPN 20 Depok, Jawa Barat. Populasi penelitian berjumlah 879 siswa. Penentuan sampel menggunakan rumus Slovin yaitu:

$$
\begin{array}{rlrl} 
& \mathrm{n}= & \frac{\mathrm{N}}{\left(1+\mathrm{Ne}^{2}\right)}(\text { Sugiyono, 2015) } \\
\mathrm{n} & =\text { jumlah sampel } \\
\mathrm{N} & =\text { jumlah populasi } \\
\mathrm{e} & =\text { batas toleransi kesalahan }=0.05
\end{array}
$$

Jumlah populasi sebesar 879 siswa, dengan taraf kesalahan 5\% maka diperoleh jumlah sampel 275 siswa.

Teknik pengambilan sampel yang digunakan dalam penelitian ini adalah simple random sampling. Sampel diperoleh dengan menulis semua nama siswa yang menjawab instrumen pada kertas kecil dan menggulungnya, kemudian disimpan dalam suatu wadah dan mengundi kertas-kertas 
tersebut sehingga diperoleh jumlah sampel yang telah ditentukan.

Pengetahuan lingkungan hidup merupakan variabel bebas (X) dalam penelitian ini. Pengetahuan lingkungan hidup diukur berdasarkan instrumen tes pilihan ganda yang terdiri dari 30 soal. Sebelum digunakan dalam penelitian, instrumen pilihan ganda yang telah divalidasi sebelumnya oleh para ahli, kemudian diujicobakan kepada responden bukan sampel. Indeks kesukaran soal dihitung menggunakan rumus menurut teori Arikunto (2013) sehingga diketahui terdapat tiga butir soal tergolong sukar, 11 butir soal tergolong sedang, dan 16 butir soal tergolong mudah. Data uji coba soal dianalisis menggunakan uji Pearson's Product Moment Correlation untuk mengetahui kevalidan setiap butir soal dan uji Cronbach's Alpha untuk mengetahui reliabilitas instrumen. Hasil analisis uji validitas menunjukkan 22 butir item dinyatakan valid karena memiliki $r_{\text {hit }}>r_{\text {tabel }}=$ 0.34 . Selanjutnya, dari uji reliabilitas diperoleh $\mathrm{r}_{\text {hitung }}=0.88$, dengan kaidah keputusan menurut Sudjiono (2012) bahwa $r_{\text {hit }}>0.70$, maka butir soal tersebut dinyatakan reliabel.

Variabel terikat (Y) adalah sikap terhadap lingkungan hidup diukur dengan angket skala Likert. Angket terdiri dari pernyataan positif dan negatif yang masing-masing berjumlah 15 pernyataan. Hasil analisis uji validitas menggunakan uji Pearson's Product Moment Correlation menunjukkan 21 butir item dinyatakan valid karena memiliki $\mathrm{r}_{\text {hit }}>\mathrm{r}_{\text {tabel }}=0.34$. Selanjutnya, dari uji reliabilitas menggunakan uji Cronbach's Alpha diperoleh $\mathrm{r}_{\text {hitung }}=0.89$, maka butir soal tersebut dinyatakan reliabel.

Pengumpulan data secara online. Penyebaran instrumen penelitian dilakukan dengan membagikan link google formulir kepada guru mata pelajaran IPA di masing-masing kelas, selanjutnya sang guru membagikan tautan tersebut kepada siswanya.

Data yang telah terkumpul kemudian dianalisis. Analisis data dilakukan secara deskriptif yaitu: menyajikan, mendeskripsikan, dan mengkomunikasikan data mentah. Penyajian data data disajikan baik dalam bentuk gambar, tabel, ataupun grafik. Selanjutnya, dilakukan pengujian persyaratan analisis menggunakan uji normalitas data dengan uji Kolmogorov Smirnov, dilanjutkan dengan uji kelinieritas regresi. Uji hipotesisnya menggunakan uji Pearson's Product Moment Correlation.

\section{HASIL DAN PEMBAHASAN}

Penelitian ini melibatkan 275 siswa-siswi SMPN 20 Depok dari siswa kelas VII, VIII, dan IX. Responden tersebar dalam 27 kelas dengan memiliki kecenderungan karakteristik yang homogen. Berdasarkan karakteristik responden pada penelitian ini maka dapat diperoleh gambaran umum mengenai responden yang dikelompokkan berdasarkan jenis kelamin dan kelas (Gambar 1 dan 2).

Frekuensi Jenis Kelamin Responden

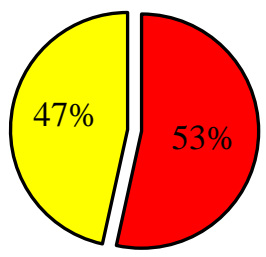

口Laki-laki $\square$ Perempuan

Gambar 1. Distribusi frekuensi jenis kelamin

Frekuensi Kelas Responden

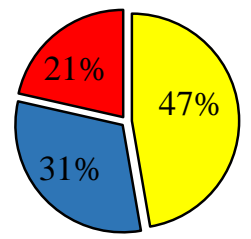

$\square 7 \square 8 \square 9$

Gambar 2. Distribusi frekuensi kelas responden

Distribusi frekuensi nilai pengetahuan dan tingkat pengetahuan lingkungan yang berasal dari jawaban para siswa dapat dilihat pada Gambar 3 dan 4. Selanjutnya pada Gambar 5 dan Gambar 6 disajikan secara deskriptif, distribusi frekuensi sikap kepedulian siswa dan tingkat kepedulian siswa terhadap lingkungan. Setelah penyajian data secara deskriptif, kemudian dilakukan uji statistik terhadap data tersebut. Dalam pengujian Kolmogorov Smirnov dengan taraf signifikansi $5 \%$, apabila $a_{\max } \leq \mathrm{D}_{\text {tabel }}$ maka data berdistribusi normal. Hasil yang diperoleh adalah sebagai berikut variabel pengetahuan lingkungan hidup $a_{\max }(0.08) \leq \mathrm{D}_{\text {tabel }}(0.81)$, berarti berdistribusi normal. Selanjutnya, variabel sikap peduli lingkungan $a_{\max }(0.05) \leq \mathrm{D}_{\text {tabel }}(0.81)$, berarti 
berdistribusi normal juga. Dari data tersebut maka diperoleh persamaan regresi, yaitu: $\widehat{Y}=75.07+$ $0.07 \widehat{\mathrm{X}}$. Hasil ini memperlihatkan bila terjadi kenaikan dari satu unit variabel $\mathrm{X}$, maka secara rata-rata variabel Y akan naik sebanyak 0.07 dan karena $\mathrm{X}$ bernilai positif, maka terdapat pengaruh positif antara variabel $\mathrm{X}$ dan variabel $\mathrm{Y}$.

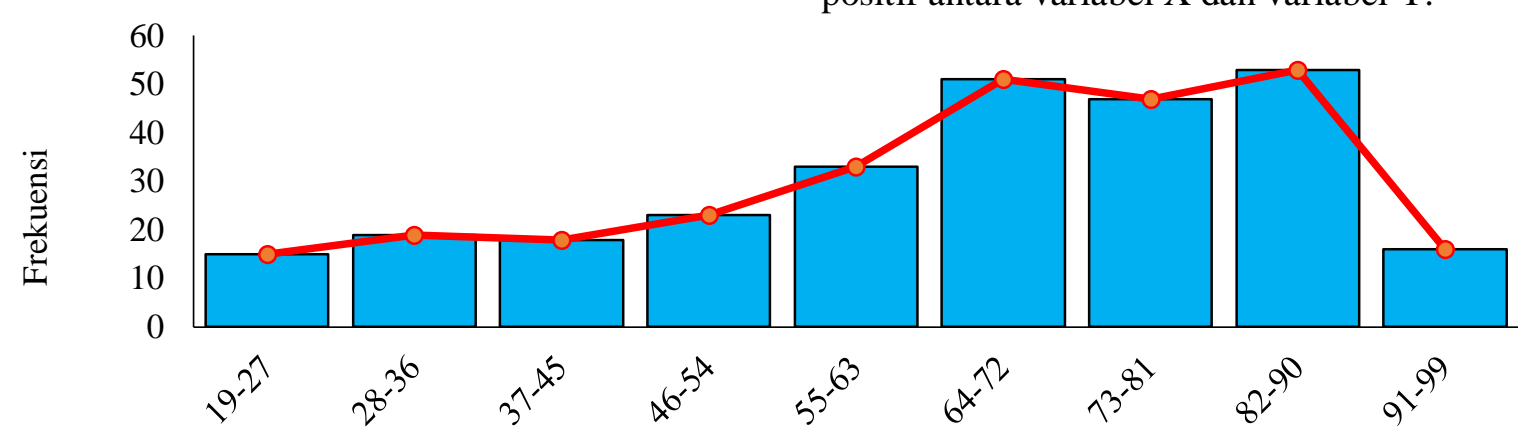

Kelas interval

Gambar 3. Diagram distribusi frekuensi nilai pengetahuan lingkungan hidup responden

Dalam uji linieritas regresi dihasilkan nilai $\mathrm{F}_{\text {hitung }}$ dengan nilai 0.77 dan nilai $\mathrm{F}_{\text {tabel }}$ sebesar 1.71 maka dapat diketahui nilai $F_{\text {hitung }}<\mathrm{F}_{\text {tabel }}$ sehingga H0 diterima. Pernyataan ini dapat ditarik kesimpulan bila model regresi memiliki pola linear.

Setelah diketahui bahwa sebaran data normal dan berpola linier, dilakukan pengujian korelasi antara pengetahuan lingkungan hidup dan sikap peduli lingkungan. Hasilnya adalah $r_{x y}$ memiliki nilai sebesar 0.17 yang artinya nilai korelasi antara pengetahuan dengan sikap peduli lingkungan hidup memiliki nilai sebesar 0.17 yang jika diinterpretasikan memiliki tingkat hubungan sangat rendah dan arah hubungan positif sempurna. Nilai Koefisien Determinasi (KD) sebesar 0.0276 atau $2.76 \%$ yang artinya bahwa pengetahuan lingkungan hidup dapat menjelaskan besarnya sikap peduli lingkungan hidup adalah $2.76 \%$ dan sisanya dipengaruhi oleh faktor lain.
Berdasarkan Gambar 6 dapat diketahui bahwa sikap rasa peduli terhadap lingkungan hidup siswasiswi di SMPN 20 Depok tergolong kategori tinggi dan sangat tinggi, hanya sedikit (1\%) yang terkategori sedang. Memiliki sikap peduli lingkungan hidup yang baik maka dampak yang akan ditimbulkan pada lingkungan akan menjadi baik serta baik buruknya suatu lingkungan sangat dipengaruhi oleh perilaku manusia. Pernyataan ini sejalan dengan pernyataan Suprayogo (2013) bahwa manusia memiliki tanggung jawab terhadap kelestarian lingkungan hidup. Oleh sebab itu, sikap peduli lingkungan hidup sangat penting dimiliki setiap manusia terutama siswa SMP yang merupakan generasi penerus bangsa karena mereka dianggap sudah dapat membedakan sikap-sikap yang memang harus dilakukan dan tidak dilakukan untuk menjaga lingkungan.

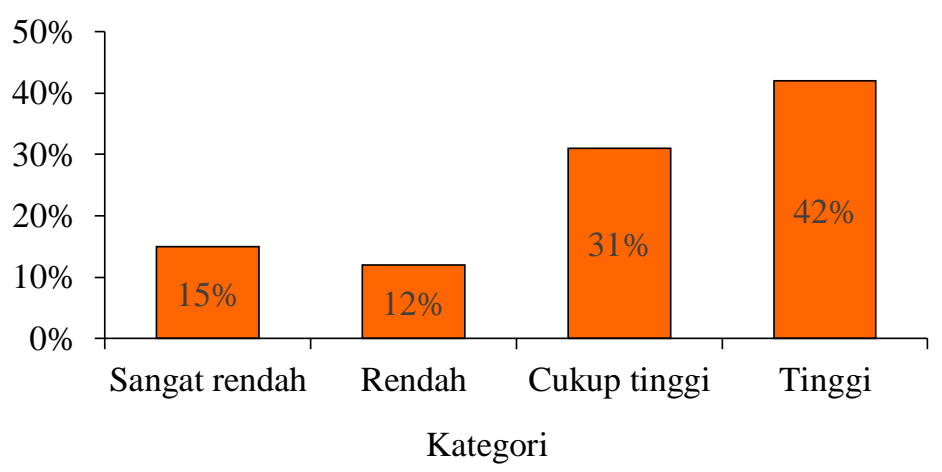

Gambar 4 Diagram tingkat pengetahuan lingkungan hidup responden

Pengetahuan lingkungan hidup merupakan wawasan yang dimiliki seseorang terkait lingkungan yang dapat memengaruhi perhatian dan sikap ekologinya. Budiman \& Riyanto (2013) 
menyatakan bahwa beberapa faktor yang mempengaruhi pengetahuan seseorang, antara lain: usia, media massa atau informasi, ekonomi, sosial, budaya, pengalaman, lingkungan, dan pendidikan. Berdasarkan Gambar 4, dapat diketahui bahwa tingkat pengetahuan mengenai lingkungan hidup yang dimiliki oleh siswa-siswi di SMPN 20 Depok tersebar, mulai dari yang rendah (27\%) hingga tinggi (73\%), yang berarti sepertiga responden terkategori memiliki pengetahuan tentang lingkungan hidup yang rendah.

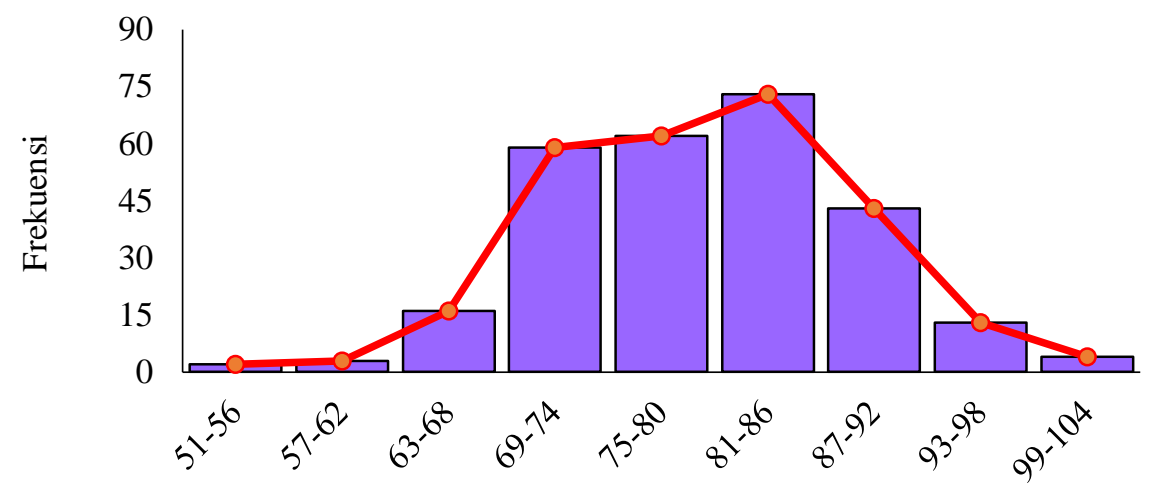

Kelas interval

Gambar 5. Diagram distribusi frekuensi sikap peduli terhadap lingkungan responden

Hasil penelitian ini sejalan dengan hasil penelitian yang dilakukan oleh Agustin \& Wiwin (2020) yaitu diperoleh hubungan yang positif antara pengetahuan lingkungan terhadap sikap peduli terhadap lingkungan siswa kelas $\mathrm{X}$ dan XI SMA Negeri 5 Jember. Hasil uji hipotesis Kendall's Tau Correlation variabel pengetahuan lingkungan dengan variabel sikap peduli lingkungan sebesar $0.000<0.05$, berarti hipotesis alternatif diterima. Hasil tersebut dapt disimpulan bahwa terdapat hubungan signifikan antara pengetahuan dengan sikap peduli lingkungan. Penelitian Suhartinah et al. (2019) juga menyimpulkan hal yang senada yaitu adanya hubungan yang positif antara sikap peduli lingkungan dengan kemampuan literasi sains siswa SMP pada materi ekosistem.

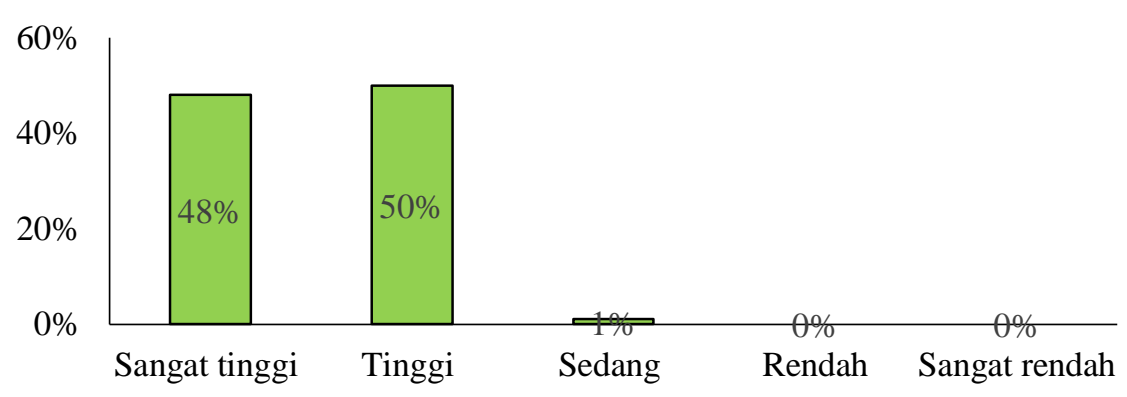

Kategori

Gambar 6. Diagram tingkat sikap peduli terhadap lingkungan responden

Mengingat nilai Koefisien Determinasi (KD) sebesar 0.0276 atau $2.76 \%$ yang artinya bahwa pengetahuan lingkungan hidup dapat menjelaskan terdapat sebesar $2.76 \%$ sikap peduli lingkungan hidup dan sisanya adalah pengaruh dari faktor lain. Siswa yang memiliki tingkat pengetahuan lingkungan hidupnya rendah tetapi sikap peduli terhadap lingkungan yang terkategori tinggi dapat disebabkan oleh faktor-faktor lainnya, tidak semata-mata karena pengetahuan yang dimilikinya. Faktor lainnya yang mempengaruhi sikap peduli lingkungan, menurut Gifford \& Sussman (2012) dalam Pertiwi et al. (2019) di antaranya adalah informasi mengenai isu 
lingkungan terkini, jenis kelamin, usia, status sosial seseorang, bangsa, ekonomi, tempat tinggal apakah di perkotaan atau di pedesaan, politik, agama, pengalaman, kepribadian, dan pendidikan.

Pengetahuan tentang kepedulian lingkungan yang dimiliki siswa terbukti belum sepenuhnya diaplikasikan dalam sikap peduli lingkungan hidup. Menurut Notoatmodjo (2011), kesadaran dalam hal menjaga lingkungan hidup, masih dalam tahap memahami saja belum sampai tahap pengaplikasian. Agar pengetahuan lingkungan hidup memiliki kontribusi yang besar, maka kondisi tersebut sangat bergantung dalam situasi penyampaian materi sehingga guru dapat menggunakan media atau alat pembelajaran yang lebih bervariasi dalam menyampaikan materi terkait isu-isu lingkungan dengan tujuan siswa tidak jenuh menerima materi yang diberikan.

Suharyat (2014) dalam Istiqomah (2019) juga berpendapat yang senada, bahwa untuk merubah siswa melalui proses pembelajaran, maka penyampaian informasi harus secara persuasif. Persuasif dapat dilakukan dengan pendekatan melalui proses menganalisa, mensintesis, dan menilai sehingga dapat diperoleh keyakinan. Selain itu, dalam penelitian Wulandari (2016) menunjukan bahwa guru dapat melakukan pemberian keteladanan terkait sikap peduli lingkungan melalui cara yang sederhana seperti membantu menghapus papan tulis setelah kegiatan pembelajaran usai, mengajak siswa untuk mengambil sampah yang berserakan, terlibat dalam program kerja bakti dalam menjaga pelestarian lingkungan sekolah, dan menegur siswa yang melanggar pelestarian lingkungan serta memberikan apresiasi atau pujian kepada siswa yang melakukan pelestarian lingkungan.

\section{KESIMPULAN}

Pada penelitian ini dikaji tentang hubungan antara pengetahuan lingkungan hidup dan sikap peduli terhadap lingkungan hidup. Hasil penelitian ini memperlihatkan bahwa pengetahuan lingkungan hidup dan sikap peduli lingkungan hidup dari siswa SMPN 20 Depok termasuk dalam kategori tinggi. Tingkat keeratan hubungan antara pengetahuan dengan sikap peduli lingkungan hidup tersebut tergolong sangat rendah dengan arah hubungan yang positif.

Melalui temuan yang diperoleh dari penelitian ini, pihak sekolah dan guru perlu mengadakan kegiatan rutin baik bulanan atau mingguan terkait menjaga kelestarian lingkungan di lingkungan sekolah agar siswa dapat lebih mengembangkan pengetahuan yang telah dimilikinya.

\section{DAFTAR PUSTAKA}

Agustin, E. E., \& Wiwin, M. (2020). Hubungan pengetahuan lingkungan terhadap sikap dan perilaku peduli lingkungan pada siswa SMAN 5 Jember Tahun Pelajaran 2018/2019. ALVEOLI: Jurnal Pendidikan Biologi, 1 (2), 82-90. https://doi.org/10.35719/alveoli.v1i2.16.

Ahmadi, R. (2018). Hubungan Pengetahuan Lingkungan Hidup dengan Sikap Peduli Lingkungan Hidup pada Siswa Kelas VIII SMP Negeri 3 Tumijajar. Skripsi. Universitas Lampung.

Aminrad, Z., Zakariya, S. Z. B. S., Hadi, A. S., \& Sakkari, M. (2013). Relationship between awareness knowledge, and attitude towards environmental education among secondary school students in Malaysia. World Applied Sciences Journal, 22 (9), 1326-1333.

Arikunto, S. (2013). Dasar-Dasar Evaluasi Pendidikan. Edisi 2. PT Bumi Aksara: Jakarta.

Azhar, A., Basyir, M. D., \& Alfitri, A. (2015). Hubungan pengetahuan dan etika lingkungan dengan sikap dan perilaku menjaga kelestarian lingkungan. Jurnal Ilmu Lingkungan, 13 (1), 36-41. https://doi.org/10.14710/jil.13.1.36-41.

Budiman., \& Riyanto, A. (2013). Kapita Selekta Kuesioner Pengetahuan dan Sikap dalam Penelitian Kesehatan. Salemba Medika: Jakarta.

Hardiningtyas, P. R. (2016). Masalah tanah dan krisis lingkungan di Bali dalam antologi puisi dongeng dari utara karya Made Adnyana Ole. Jurnal Atavisme, 19 (1), 45-59. http://doi.org/ 10.24257/atavisme.v19i1.180.45-59.

Istiqomah. (2019). Sikap peduli lingkungan peserta didik di MAN-1 Pekanbaru sebagai sekolah adiwiyata. Dinamika Lingkungan Indonesia, $6(2)$, 95-103. http://dx.doi.org/10.31258/dli.6.2.p.95-103.

Martini, M. (2019). Hubungan antara pengetahuan lingkungan dengan perilaku prolingkungan Sekolah Adiwiyata (studi kasus SDN 21 Taluak Kab. Agam). Rang Teknik Journal, 2(1), 71-78.

Muliana, R., Hamama, S. F., \& Zamzami, Z. (2018). Hubungan pengetahuan lingkungan terhadap sikap siswa pada pengelolaan kebersihan di sekolah. Jurnal Dedikasi Pendidikan, 2(1), 8-13.

Munawar, S., Heryanti, E., \& Miarsyah, M. (2019). Hubungan pengetahuan lingkungan hidup dengan kesadaran lingkungan pada siswa 
Sekolah Adiwiyata. LENSA: Lentera Sains, 9(1), 22-29. https://doi.org/10.24929/lensa.v1i1.58.

Notoatmodjo, S. (2011). Pendidikan dan Perilaku Kesehatan. PT. Rineka Cipta: Jakarta.

Pertiwi, O. P., Lengkana, D., \& Surbakti, A. (2019). Perbandingan pengetahuan dan sikap peduli lingkungan di sekolah kawasan TNWK dengan perkantoran. Jurnal Bioterdidik, 7 (3), 59-66.

Sirait, N. F. (2012). Hubungan Tingkat Pengetahuan dan Kemampuan Berpikir Kritis Terhadap Perilaku Mencintai Lingkungan Siswa SMA Negeri Se-Kota Medan Tahun 2012. Tesis. Universitas Negeri Medan.
Sudjiono, A. (2012). Pengantar Evaluasi Pendidikan. PT Rajagrafindo Persada: Jakarta. Sugiyono. (2015). Metode Penelitian Pendidikan Pendekatan, Kuantitatif, Kualitatif dan $R \& D$. Alfabeta: Bandung.

Suhartinah, S., Hidayati, Y., Qomaria, N., \& Hadi, W. P. (2019). Studi korelasi antara sikap peduli lingkungan dengan kemampuan literasi sains siswa SMP pada materi ekosistem. Natural Science Education Reseach, 2(1), 77-84.

Suprayogo, I. (2013). Pengembangan Pendidikan Karakter. UIN-Maliki Press: Malang.

Wulandari, T. V. (2016). Pendidikan lingkungan hidup dalam membentuk sikap peduli lingkungan siswa di SMPN 4 Jombang. Kajian Moral dan Kewarganegaraan, 3(4), 1153-1167.

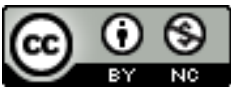

This work is licensed under a Creative Commons Attribution-NonCommercial 4.0 International License 